\title{
The Reproductive Behavior of Indian Leopards (Panthera pardus fusca)
}

\author{
Boon Allwin ${ }^{1}$, Kalignan PA ${ }^{2}$, Pradeep Nag BS ${ }^{3}$, Gopikrishnan D ${ }^{3}$ and Nishit S Gokarn ${ }^{4}$
}

${ }^{1}$ Department of Wildlife Science, Madras Veterinary College, TANUVAS, Chennai, Tamil Nadu, India

${ }^{2}$ Zoo Veterinarian, Bannerghatta Zoological Park, Karnataka, India

${ }^{3}$ Department of Gynecology, Madras Veterinary College, TANUVAS, Chennai, Tamil Nadu, India

${ }^{4}$ Department of Surgery, Madras Veterinary College, TANUVAS, Chennai, Tamil Nadu, India

\begin{abstract}
Leopards are very elusive and elegant cats and their reproductive behavior has been a challenging one to document. All behavioral observations were carried out after the daily cleaning activities of the zoo keepers, from a vantage point undisturbed and unhindered. The animals were observed for 2 hours at a frequency of 4 times a day. A total of 38 leopards were included in the study comprising of 33 animals (17 males and 16 females) from Bannerghatta National Park and 5 animals ( 3 males and 2 females) from Aringar Anna Zoological Park. The study focused on the mating behavior of leopards which was divided into pre-copulatory period, copulatory period and post-copulatory period, invariable of the number of animals, the total number of matings were regarded prime in this study. The behavioral oestrus periods were calculated as the difference from the day of the first observed behavioral signs shown by the animal to the last observed day of the oestrus signs. The inter-oestrus interval was calculated from the last day of the previous observed behavioral oestrus to the first day of the next observed behavioral oestrus. The behavioral indicators are documented and the findings are discussed.
\end{abstract}

Keywords: Leopard; Oestrus behavior; Sexual behavior

\section{Introduction}

The abundant growth in the human population has resulted in the extensive degradation of the wild life habitat, which poses main threat to the conservation of wild felids [1]. Conservation of these wild felids could be achieved only by reducing the human wild life conflict and by the proper and through understanding of their reproductive physiology [2]. However, the data regarding the quantification of the reproductive parameters requires a collection over multiple generations [3] which make the study laborious. Although enormous studies had been done exploring the reproductive behaviors and reproductive success in lions [4,5], cheetahs [6], tigers [7] and leopards, the basic behaviors of estrus and mating has not yet been elucidated in these wild felids which are essential for understanding the reproductive physiology of these species. Leopards have a wide range of distribution with the exception in the Himalayas and the desert regions. The elusiveness and behavioral flexibility of the leopards allow this species to survive near villages and human settlements. Although studies had been done on the behaviours of reproduction in male leopards [8], relatively few data are available for the reproductive behaviour in females. Hence the present was aimed to elucidate the estrus and mating behaviours of the leopards in captivity.

\section{Study area}

The entire study was carried out at two different geographical locations. The first at the Bannerghatta Biological Park, popularly known as BBP, has been an integral part of Bannerghatta National Park and emerged out as an independent establishment during the year 2002 $\left(12.8009^{\circ} \mathrm{N}, 77.5777^{\circ} \mathrm{E}\right)$. The second at Arignar Anna Zoological Park (AAZP), Vandalur located $32 \mathrm{kms}$, South of Chennai on the eastern side of the Grand Southern trunk road (NH 45) $\left(12.8781^{\circ} \mathrm{N}, 80.0859^{\circ}\right.$ E) in the Vandalur reserve forest of Kancheepuram district and is one of the biggest zoos in India extending over 510 hectares.

\section{Study animals}

A total of 38 leopards were included in the study comprising of 33 animals (17 males and 16 females) from Bannerghatta National Park and 5 animals ( 3 males and 2 females) from Aringar Anna Zoological
Park. The study focused on the mating behavior of leopards which was divided into pre-copulatory period, copulatory period and postcopulatory period, invariable of the number of animals, the total number of matings were regarded prime in this study. All the animals in the study have attained sexual maturity and are considered adults.

\section{Husbandry}

The zoo keepers start their work by 08:30-09:00 hrs. The animals are either retained in the off-exhibit enclosure or let into the on-exhibit enclosures on a rotation basis after routine cleaning procedures. The animals were usually housed indoors in individual enclosures at night. The animals are not exhibited on Tuesdays when the zoo remains closed. All animals were fed a diet of raw beef with bones about 4-5 $\mathrm{kg}$ daily at around 16:30 hrs except on Tuesdays providing ad libidum water on all days. All the female animals had visual, auditory and/ or olfactory communication with male con-specific. The animals are annually vaccinated against Feligen and are dewormed quarterly.

\section{Behavioral observations}

General behavior: All behavioral observations were carried out after the daily cleaning activities of the zoo keepers, from a vantage point undisturbed and unhindered. The animals were observed for 2 hours at a frequency of 4 times a day. Initial periods of observation were spent in characterization of various behaviours as behavioral states and as behavioral events as defined by Martin and Bateson [9] and an ethogram were duly prepared. All observations were done

${ }^{*}$ Corresponding author: Boon Allwin, Research Scholar, Department of Wildlife Science, Madras Veterinary College, TANUVAS, Chennai, Tamil Nadu, India, Tel: +914425304000; E-mail: boonallwin@gmail.com

Received June 17, 2016; Accepted June 29, 2016; Published July 04, 2016

Citation: Allwin B, Kalignan PA, Nag PBS, Gopikrishnan D, Gokarn NS (2016) The Reproductive Behavior of Indian Leopards (Panthera pardus fusca). J Vet Sci Technol 7: 358. doi:10.4172/2157-7579.1000358

Copyright: ( 2016 Allwin B, et al. This is an open-access article distributed under the terms of the Creative Commons Attribution License, which permits unrestricted use, distribution, and reproduction in any medium, provided the original author and source are credited. 
with naked eye and with the aid of a pair of binoculars $(10 \times 50)$ when required. The timing was maintained using a digital stop watch.

The various macro-environment data viz. maximum and minimum temperature, rainfall, humidity, photoperiod were recorded for the study area on a daily basis. The temperature and humidity of the study animal houses were recorded on a daily basis as per standard procedures.

Behavioral events are those behavioral patterns that are of relatively short duration such as discrete body movements, vocalizations etc., which could be approximated as points in time. Behavioral states are those behavioral patterns that are of relatively long duration, such as prolonged activities or body postures.

For analysis, the behavioral states were broadly classified as resting behaviour and activity behaviour. The behavioral states like sleeping, lying, sitting, grooming were grouped under resting behaviour while walking, standing, stereotypic pacing were grouped under activity behaviour.

Oestrous behaviors: The animals were focally observed [10] for the occurrence of the 6 established feline signs characteristic of oestrus viz. vocalization, rubbing, rolling, urine marking, lordosis and mounting [11]. The observations were recorded on a specially designed check sheet in 1 minute blocks during each of the 60 minutes sampling period.

The behavioral oestrus periods were calculated as the difference from the day of the first observed behavioral signs shown by the animal to the last observed day of the oestrus signs. The inter-oestrus interval was calculated from the last day of the previous observed behavioral oestrus to the first day of the next observed behavioral oestrus.

Sexual behaviors: The sexual behaviors, when mating was allowed, were observed and recorded in toto (totally, entirely and completely). A qualitative description of the sexual act, pre- copulatory, copulatory and post copulatory behaviour was recorded. Quantitative measurement of the sexual behaviours with reference to total number of mating, the frequency of mating, the mating periods, inter-mating interval was also recorded.

\section{Results}

The entire findings of this study between Bannerghatta and Arignar Anna Zoological Park will be treated as the same unless and until specified.

\section{Oestrus behavior}

The following behavioral indicators of oestrus were observed and recorded during the course of this study.

Vocalization: The female leopards in oestrus were observed to have increased frequency of vocalization. This was further sub classified into 3 types.

- A long low sound like expelling air through the nostrils This was mainly the greeting call exhibited by both the sexes sounding like an expiratory grunt

- "Calling" - These were long loud vocalizations - which lasted more than 5 seconds. The calling was usually in bouts $\geq 5$ per calling.

- "Moaning" - These were long vocalizations but not louder, sometimes also observed during the greeting between the sexes.

Rubbing: Rubbing of the face, flank and entire body against the walls, cage bars were observed. Rubbing was prominent when a male leopard was present in the adjacent cage. Rubbing also characteristically indicated a typical feline sexual behavior.

Crouching, rolling and position: Turning over and over on the back and writhing on the back was observed. Elevation of rear quarters and extension of back (lordosis), head rubbing, rolling presentation of vulva and constant lashing of the tail was well pronounced Rolling was almost always accompanied with a moaning vocalization. Sometimes rolling was not completed - "Quarter rolls and half-rolls".

\section{Urine marking}

Two types of urine marking were observed namely spraying of urine and squatted urination. The frequency of urine spraying was relatively increased during the oestrus period. The female leopard stood erect, tail raised and actively sprayed a small quantity of the urine onto the walls and cage bars. Urine spraying was found to be particularly more on the cage door when a male was housed adjacently. The leopard chose a specific spot for urination within the enclosure and held snarling head "a typical feline aggressive gait".

\section{Flehmen}

The male leopards were observed to sniff the walls, floors, cage bars and exhibited a snarling facial expression as how in any leopard will react in response to pain as markedly noted in other leopards with the ears positioned backwards

Vaginal discharge: Slight white mucus discharge was also observed during the oestrus.

Genital licking: Intermittent licking of genitalia was also a frequent feature during the oestrus period.

\section{Mounting and lordosis}

Apart from these indicators, the leopards were observed to be restless and constantly pacing and preferred a dark location inside the animal enclosure, Loss of appetite was also a regular feature. Standing and looking into the male's cage was also observed. Those leopards that exhibited the estrous behaviours were taken for the study. The behavioral oestrus periods and the inter-oestrus interval for the individual leopards as well as for the species as a whole are given in Table 1.

\section{Sexual behavior}

The various aspects of the sexual behaviour observed are presented below.

\section{Mating behaviour}

Pre-Copulatory behavior: It was observed that almost always it was the female who initiated the mating. The female was seen to greet the male with a long low sound and the male responded. The female showed an interest in the male, approached him and rubbed her face with that of the male head rubbing or flank rubbing. This initiated the male to move towards the female and she led him on with her tail raised and lashing from side to side (between $45^{\circ}$ to $135^{\circ}$ ), after repeated rubs, tail lashes and tail rubs the female attained a typical lordosis posture presenting her to the male. Simultaneously the male approached the female from behind for mounting.

Copulatory behavior: The male Leopards mounted on the female and positioned themselves by arching his back and thrusting forward for intromission as typically seen in domestic felines. During this act both the male and the female exhibited a typical snarling expression. Following the intromission, the male emitted a characteristic prolonged 


\begin{tabular}{|c|c|c|}
\hline Leopard No. & Behavioural oestrous & $\begin{array}{l}\text { Behavioural inter- } \\
\text { oestrous interval }\end{array}$ \\
\hline 1 & 8 & 29 \\
\hline 2 & 6 & 28 \\
\hline 3 & 7 & 31 \\
\hline 4 & 6 & 32 \\
\hline 5 & 8 & 28 \\
\hline 6 & 9 & 26 \\
\hline 7 & 7 & 27 \\
\hline 8 & 8 & 31 \\
\hline 9 & 7 & 26 \\
\hline 10 & 9 & 34 \\
\hline 11 & 6 & 33 \\
\hline 12 & 9 & 29 \\
\hline 13 & 8 & 30 \\
\hline 14 & 7 & 30 \\
\hline 15 & 9 & 25 \\
\hline 16 & 8 & 27 \\
\hline 17 & 6 & 32 \\
\hline 18 & 8 & 31 \\
\hline Mean \pm SE & $7.56 \pm 0.95$ & $29.39 \pm 0.62$ \\
\hline
\end{tabular}

Table 1: The behavioral estrus periods and the inter-estrous interval for the individual leopards.

copulatory growl indicating the act of ejaculation, the duration of which varied, before leaning forward to grip the neck of the female

Post-Copulatory behavior: The male dismounted from female by jumping. Sometimes it was observed that the female gave a jerk to dislodge the male and tried to hit him with her paw with a growl. At times the jerk from the female was heavy and attempts to bite the male were clearly exhibited.

The male and the female seemed to exhibit different post copulatory behaviours. The female following the copulation engaged in one or more of the following behaviours: rolling, grooming, genital licking, lying sternal or lateral, walking or sleeping. The male on the other hand spent most of the time walking in the moat, lying, urine spraying and sleeping. Both the males and females were also observed to spend their post copulatory activity partly inside the water trough kept for watering within the enclosure.

After each mating, the animals took some time before they mated again. The inter-mating period or refractory period was calculated as the time from the previous dismount to the time of next successful mount. The refractory period was calculated to be $56.46 \pm 0.15$ minutes $(\mathrm{n}=45)$ on an average. The actual range extended from 0.93 minutes to 181 minutes.

\section{Period of receptivity}

This was calculated as the number of days permitted by female leopard for copulation by the male. In this study, the number of days was ranging from 6 to 9 days.

Mating time: This was calculated as the time from mounting to the time of dismounting. Successful mounts (in which intromission was present) were only considered for mating time. The average mating time was $40.38 \pm 0.22$ seconds $(n=45)$ with the range extending from 12.36 to 80.03 seconds. The mating was observed only during the day time and since the animals were separated in the night. A total of 45 matings were observed during the entire study period and of these 26 (57.77\%) took place in the forenoon session (9.30 AM-12.00 AM) while the remaining $19(42.22 \%)$ took place in the afternoon session. (12.01-
5.00 PM). There was not much interference during the feeding time and mating took place during the feeding time also.

Unsuccessful matings: Of the 72 approaches observed, only 45 $(62.5 \%)$ resulted in successful matings. The remaining 27 (37.5\%) were unsuccessful. The unsuccessful matings were either mounts with no intromission or just check rubbing, flank rubbing only. Of the 72 interactions involved $55(76.38 \%)$ were initiated by the female while only $17(23.61 \%)$ were initiated by the male.

\section{Discussion}

During the present study, apart from the established feline oestrus signs, the following observations were recorded - increase in activity behavior or restlessness, loss of appetite, "flehmen" and vaginal discharge previous studies by various authors [12-17] in tigers indicated that restlessness and pacing is a constant feature of oestrus as against the complete apathy females display during anoestrus which is characterized by resting quietly. It is noteworthy mention of Estep and Dewsbury [18] who stated that an increase in general activity manifested as increased locomotion, restlessness, or increased social interactions is coincident with oestrus in many species as observed in the present study. During this study, it was also observed that the oestrus signs observed and recorded in leopards include loss of appetite, lashing of tail, increase in activity behaviour and flehmen. Social behaviours like rubbing perineal area, lordosis, mounting, getting under, being mounted reported by Schmidt et al. [19].

Flehmen reaction, previously unreported in leopards was exhibited by 8 of the leopards out of 18 leopards during the alternate cycles individually. This detection was very rare and was not observed in the other leopard and in the same Leopard during subsequent cycles. Urine scent marking also was a less prominent sign as compared to that of tigers. Vocalization, rubbing, rolling were prominently associated with oestrus and varied from animal to animal with regards to the intensity of expression and rolling was almost always accompanied by a moaning sound.

Lashing of tail was observed in all the Leopards and this was prominent during its pacing when the male was near the adjacent cage door. This behavior was not observed in the absence of the male and it strongly suggests invitation for mating. Similar "lashing of tail" has been reported by Schaller [20] in lionesses.

The oestrus periods determined for the leopards was $7.55 \pm 0.95$ days ( $\mathrm{n}=18,6-9$ days). This is in accordance with the earlier studies 3-14 days [21], 4-14 days [22], 4-11 days [23] and 7 days. The interoestrus period was found to be $29.38 \pm 0.62$ days $(n=18,26-34$ days) in two leopards. This was in contradiction to the earlier reports by Sadlier [21]-43 days (13-112) and Schmidt et al. [19] 7-8 weeks and Wildt [8]46 days. Felines normally being induced ovulators ovulation occur after 2-3 matings and the period of exhibiting estrus varies within the oestrus period. These felids show a gap known as the "oestral recess" for a period varying from 5-7 days. After this period typical signs of estrus were recorded and mating progressed. However it was beyond the scope of this study to understand the endocrine basis of such occurrences for which, the respective hormones have to be assessed.

\section{Vaginal discharge}

Vaginal discharge was observed in the study for the first time. Acharjyo et al. [13] stated that the external genitalia of tigress in oestrus was swollen which was coinciding with the findings of this study and 15 (83.33\%) of the leopards exhibited these signs which can be a reliable 
indicator for assessing oestrus. While Feldman and Nelson [24] argued that the vulvar labiae of the female cats are relatively nonresponsive to oestrogen and they remain small and covered with hair during the proestrus and oestrus Vaginal discharge was well appreciated in 5 $(27.77 \%)$ of the leopards under study during oestrus and hence this can be regarded as a indicator for oestrus in Leopards.

Urine marking was observed to be negatively correlated with oestrus by Kleiman [12] in Bengal tigers. However, in this study, urine marking was significantly associated and positively correlated with oestrus and was exhibited by all the leopards during the estrus period. There were individual variations in the intensity of expression. This is in accordance with Kleiman [12] who found that, in felids, individual females differ in the manner of displaying oestrus and that all females may occasionally exhibit these patterns at one time or another.

\section{Sexual behavior of leopards}

Mating behavior: Mating behavior has been earlier described by Acharjyo et al. [13] and by Palita et al. [17] in captive tigers of Nandankannan Biological Park, Orissa. The observations in this study concurred with the earlier reports. However, while Acharjyo et al. [13] states that mating was always initiated by the female tigress, it was not so in this study as 72 interactions involved 55 (76.38\%) were initiated by the female while only 17 (23.61\%) were initiated by the male. The neck grip was not always observed during the mounting but before dismounting, the male invariably gripped the neck of the female Schaller [20] in lions and Morris in cats contend that the neck bite before dismounting is actually a "behaviour trick" played by the male to protect himself from assault by the female after dismounting since the withdrawal of the penis causes considerable pain in the female as observed in the study. All cats have evolved a "freeze" reaction being taken by the neck bite and this temporary immobilization of the female allows the male to jump to safety. It was observed as in the earlier studies $[13,17]$ that the penis remained outside for sometime after the post copulatory jumping and the raised tail condition observed while jumping is probably to maintain the balance of the body.

Mating time: The average mating time was $40.38 \pm 0.22$ seconds $(\mathrm{n}=45)$ with the range extending from 12.36 to 80.03 seconds. This varies from that of Acharjyo et al. [13] who reported 8-35 seconds, 0.5 to 3 minutes [14] and 7.35 seconds [17].

Inter-mating period: The inter-mating period was calculated to be the refractory period was calculated to be $56.46 \pm 0.15$ minutes $(\mathrm{n}=45)$ on an average. The actual range extended from 0.93 minutes to 181 minutes. Acharjyo et al. [13] reported the inter-mating period to vary from 20 minutes to several hours, while Palita et al. [17] gave the range of 2-70 minutes. The present observations were in coinciding correlation with these reports.

Post-copulatory behaviors: The post copulatory behaviors recorded in the present study were similar to those reported earlier [13,17].

\section{Unsuccessful matings}

Of the 72 approaches observed, only 45 (62.5\%) resulted in successful matings. The remaining 27 (37.5\%) were unsuccessful. The unsuccessful matings were either mounts with no intromission or just check rubbing, flank rubbing only [25]. Of the 72 interactions involved $55(76.38 \%)$ were initiated by the female while only 17 (23.61\%) were initiated by the male. This is in agreement with the observations of Acharjyo et al. [13] and Palita et al. [17].

\section{Conclusion}

The overall finding of this study was an effort to document the sexual behavior of this elusive feline, there is still paucity in the reproductive details of these cats. An elaborate study is essential with dedicated individual animals to understand more about their physiological, psychological governance.

\section{References}

1. Kitchener A (1991) The Natural history of wild cats. Comstock Publishing Associates, Ithaca, New York, USA

2. Holt WV, Pickard AR, Rodger JC, Wildt DE (2003) Reproductive science and integrated conservation. Cambridge University Press, Cambridge, United Kingdom.

3. Clutton-Brock TH (1988) Reproductive success: Studies of individual variations in contrasting breeding systems. University of Chicago Press, Chicago, Illinois, USA.

4. Packer C, Herbst L, Pusey AE, Bygott JD, Hanby JP, et al. (1988) Reproductive success of lions. In: Reproductive Success. Clutton Brock TH (Editor). Univ. Chicago Press, Chicago, USA, p: 363383.

5. Meena V (2009) Variation in social organization of lions with particular reference to the Asiatic Lions Panthera leo persica (Carnivora: Felidae) of the Gir forest, India. Journal of Threatened Taxa 1: 158165.

6. Kelly MJ, Laurenson MK, FitzGibbon CD, Collins DA, Durant SM, et al. (1998) Demography of the Serengeti cheetah (Acinonyx jubatus) population: the first 25 years. J Zool 244: 473-488.

7. David Smith JL, McDougal C (1991) The Contribution of Variance in Lifetime Reproduction to Effective Population Size in Tigers. Conservation Biology 5 : 484-490.

8. Wildt DE, Phillips LG, Simmons LG, Chakraborty PK, Brown JL, et al. (1988) A comparative analysis of ejaculate and hormonal characteristics of the captive male cheetah, tiger, leopard, and puma. Biol Reprod 38: 245-255.

9. Martin P, Bateson P (1995) Measuring Behaviour: An introductory guide Cambridge University Press.

10. Altmann J (1974) Observational study of behavior: sampling methods. Behaviour 49: 227-267.

11. Michael RP (1961) Observations upon the sexual behaviour of the domestic cat (Felis catus L.) under laboratory conditions. Behaviour 18: 1-24.

12. Kleiman DG (1974) Patterns of behavior in hystricomorph rodents. In: The Biology of hystricomorph rodents: the proceedings of a symposium held at the Zoological Society of London on 7 and 8 June. Rowlands IW, Weir BJ (Eds.) Academic Press, UK.

13. Acharjyo LN, Mishra CG (1981) Some notes on the longevity of two species of Indian wild cats in captivity. Journal of the Bombay Natural History Society 78: $155-156$

14. Seager SWJ, Demorest CN (1986) Reproduction in captive wild carnivores In: Zoo and Wild Animal Medicine. 2nd edn. Fowler ME, Miller RE (Eds.) W. B. Saunders, Philadelphia, USA, pp: 852-881.

15. Seal US, Plotka ED, Smith JD, Wright FH, Reindl NJ, et al. (1985) Immunoreactive luteinizing hormone, estradiol, progesterone, testosterone, and androstenedione levels during the breeding season and anestrus in Siberian tigers. Biol Reprod 32: 361-368.

16. Tilson R, Soemarna K, Ramono W, Sukumar R, Seal US, et al. (1994) Asian Elephant in Sumatra. Population and Habitat Viability Analysis. Minnesota: CBSG.

17. Palita SK, Patra AK, Patnaik MR (1996) Studies on the reproductive behaviours of tiger (Panthera tigris Linn.) in captivity. Readings in Behaviour, pp: 188-197.

18. Estep DQ, Dewsbury DA (1996) Mammalian reproductive behavior. In: Wild Animals in Captivity. Kleiman DG, Allen ME, Thompson KV, Lumpkin S (Eds.). University of Chicago Press, Chicago, USA, pp: 379-389.

19. Schmidt AM, Hess DL, Schmidt MJ, Lewis CR (1988) Serum concentrations of oestradiol and progesterone and frequency of sexual behaviour during the normal oestrous cycle in the snow leopard (Panthera uncia). J Reprod Fertil 82: 43-49.

20. Schaller GB (1972) The Serengeti lion. University of Chicago Press, Chicago, Illinois, USA.

21. Sadleir RMFS (1966) Notes on reproduction in the larger Felidae. International Zoo Yearbook 6: 184-187. 
Citation: Allwin B, Kalignan PA, Nag PBS, Gopikrishnan D, Gokarn NS (2016) The Reproductive Behavior of Indian Leopards (Panthera pardus fusca). J Vet Sci Technol 7: 358. doi:10.4172/2157-7579.1000358

Page 5 of 5

22. Desai JH (1975) Observations on the reproductive biology and early postnatal development of the panther, Panthera pardus L., in captivity. Journal of the Bombay Natural History Society 72: 293-304.

23. Acharjyo LN, Patnaik SK (1985) Observations on some aspects of reproduction among the panthers (Panthera pardus) of Nandan-Kanan Biological Park, Orissa. Indian Journal of Forestry 8: 8-14.
24. Feldman EC, Nelson RW (1996) Canine and feline endocrinology and reproduction. 2nd edn. WB Saunders Company, Philadelphia, USA.

25. Daniel JC (2009) The leopard in India: A natural history. Natraj Publishers, Dehra Dun, India, p: 228. 